\title{
Heterogeneity of the barrier properties of the colon in rat
}

\section{Viktoria Bekusova ${ }^{1}$, Ilyas Fatyykhov ${ }^{1}$, Salah Amasheh², and Alexander Markov ${ }^{1}$}

1Department of General Physiology, Faculty of Biology, Saint Petersburg State University, Universitetskaya nab., 7-9, Saint Petersburg, 199034, Russian Federation

${ }^{2}$ Institute of Veterinary Physiology, Freie Universität Berlin,

Oertzenweg 19b, Berlin, 14163, Germany

Address correspondence and requests for materials to Viktoria Bekusova,

v.bekusova@spbu.ru

\section{Abstract}

The incidence of colorectal cancer in different parts of the large intestine is not the same, as tumors more often appear in the distal part of the colon compared to the proximal one. The purpose of this study was to investigate heterogeneity of the barrier properties of the colon and clarify the effects of Prostaglandin E2 and interleukin-1 beta on its different parts. An in-depth analysis of short circuit current, transepithelial electrical resistance and paracellular permeability for sodium fluorescein in Ussing chambers showed that the proximal part of the colon was less permeable compared to the distal one and the substances had different effects on the parameters of permeability in different parts of the colon. We suppose that heterogeneity of the barrier properties of the colon and various effects of their regulation by local molecular agents may determine different incidence of pathologies in the colon.

Citation: Bekusova, V., Fatyykhov, I., Amasheh, S., and Markov, A. 2021. Heterogeneity of the barrier properties of the colon in rat. Bio. Comm. 66(2): 160-170. https://doi.org/10.21638/spbu03.2021.207

Authors' information: Viktoria Bekusova, PhD, Associate Professor, orcid.org/00000002-2371-8969; Ilyas Fatyykhov, Bachelor of Sci. in Biology, Student, orcid.org/00000003-3607-2447; Salah Amasheh, Dr. rer. nat., Professor, orcid.org/0000-0002-63651949; Alexander Markov, Dr. of Sci. in Biology, Professor, Head of Department, orcid.org/0000-0002-2867-044X

Manuscript Editor: Anna Malashicheva, Laboratory of Regenerative Biomedicine, Institute of Cytology, Russian Academy of Sciences, Saint Petersburg, Russia; Laboratory of Molecular Cardiology, Almazov National Medical Research Centre, Saint Petersburg, Russia

Received: November 10, 2020;

Revised: December 23, 2020;

Accepted: December 29, 2020.

Copyright: (c) 2021 Bekusova et al. This is an open-access article distributed under the terms of the License Agreement with Saint Petersburg State University, which permits to the authors unrestricted distribution, and self-archiving free of charge.

Funding: This research was sponsored by the Grant of RFFI (20-04-01050).

Ethics statement: The studies were carried out in accordance with the guidelines of FELASA (Mahler et al., 2014) and approved by the Ethics Committee for Animal Research St. Petersburg State University (Approval No 131-03).

Competing interests: The authors have declared that no competing interests exist.
Keywords: rat, colon, heterogeneity, prostaglandin E2, interleukin-1beta, Ussing chamber, short circuit current, transepithelial electrical resistance, intestinal permeability, barrier properties

\section{Introduction}

The morphology and functions of the proximal and distal colon show differences which are reflected by the fact that the incidence of colorectal cancer in these parts is also different, as tumors more often appear in the descending colon than in the ascending one (Perse and Cerar, 2011; Bekusova et al., 2017). Bowel diseases are accompanied by a change in the barrier properties; however, the role of impaired barrier function and heterogeneity of the barrier properties of the colon for the development of its pathologies have not yet been clarified.

Comparative studies of the barrier properties of different parts of the colon were presented by different authors in the 1960s-1980s. Some authors reported less pronounced barrier properties of the proximal part of the colon compared to the distal one (Yau and Makhlouf, 1975; Fromm and Hegel, 1978), while others studies had opposite results (Edmonds, 1967; Rubsamen et al., 1983). Clauss et al. showed that the electrophysiological parameters of the barrier properties of rabbit colons were different depending on the location of the segment (Clauss and Hornicke, 1984). The short-circuit current was relatively high in the proximal rabbit colon, yet lower in the middle part and high again in the distal part.

In our previous study, we assumed that the differences in barrier properties of different parts of the colon may be due to the surface folds of the proximal part (Bekusova et al., 2018). So, the tissue samples of the proximal colon have a larger surface area than the samples of the distal one. Correction of the electrophysiological data by taking into consideration a correction factor was previously used to compare the barrier properties in segments of the small intestine (Markov et 
al., 2016), but this has not yet been employed in studies of colonic barrier properties.

We have previously shown that tumor-adjacent tissues have increased paracellular permeability and hypothesized that a tumor can negatively affect neighboring tissues (Bekusova et al., 2018). Diseases of the large intestine are accompanied by increased cytokines and eicosanoids secreted by the intestinal wall, endothelium and associated immune cells (Capone et al., 2016). It has been shown that the epithelial cells of the intestinal epithelial culture IPEC-J2 are capable of producing proinflammatory cytokines, although these cells are nontransformed (Brosnahan and Brown, 2012). The ability to secrete cytokines is also typically found in tumor cells (Zielinska et al., 2018).

Prostaglandin E2 (PGE2) and interleukin-1beta (IL-1 $\beta$ ) are the substances which are elevated in large intestine diseases and participate in the development of pathologies (Kamiyama et al., 2006; Sheng et al., 2006; Al-Sadi et al., 2012; Carmi et al., 2013; Voronov et al., 2013; Safdari et al., 2016; Zielinska et al., 2018). However, their effect on the barrier properties of different parts of the colon has not been studied yet.

Studies have shown that IL- $1 \beta$ causes an increase in the permeability of the tight junctions of Caco- 2 cells (Al-Sadi, Boivin and Ma, 2009) and alters the permeability of various epithelia (Coyne et al., 2002; Abe et al., 2003; Yamagata et al., 2004). Studying the effect of cytokines on the distal part of the colon in Ussing chambers showed that it was IL- $1 \beta$ that increased the short-circuit current; however, it did not have a direct effect on epithelial cells, but enlarged the production of PGE2 (Bode et al., 1998).

The aim of the study was to assess the barrier properties of the proximal and distal colon and to investigate the effects of PGE2 and IL-1 $\beta$ on epithelial permeability and barrier function of different parts of the colon for the first time.

\section{Materials and methods}

Male Wistar rats $(\mathrm{N}=26)$ aged 1.5 months were bred at the vivarium of Saint Petersburg State University. Animals were kept under a standard light/dark cycle $(12 \mathrm{~h}$ light: $12 \mathrm{~h}$ dark) at $22 \pm 2{ }^{\circ} \mathrm{C}$ with ad libitum access to tap water and complete pelleted feed (Delta Feeds, BioPro, Russia). All chemicals were obtained from Sigma Aldrich (Taufkirchen, Germany).

\section{Experimental design}

Two methodological approaches were employed. The first one was ex vivo, which allowed stimulation of the preparations directly in the Ussing chamber. We applied both PGE2 and IL-1 $\beta$. The second methodological ap- proach was in vivo + ex vivo, which was used only for PGE2 in accordance with its prolonged action: first, in vivo incubation of the colon with addition of PGE2 into the lumen of anesthetized animals, followed by incubation with PGE2 ex vivo in the Ussing chamber.

I. The rats were decapitated with a guillotine. We cut the large intestine of the rats into 8 segments, with 2 segments of proximal colon, 5 segments of distal colon, and 1 segment of the rectum, in accordance with the mapping scheme developed in the previous study (Bekusova et al., 2018). A total of 18 male Wistar rats were randomly subdivided into four groups: three experimental groups and a control group. A total of 56 segments from 7 rats in the control group were not exposed to PGE2 and IL-1 $\beta$, whereas segments from 11 rats from the experimental groups were incubated with the substances in Ussing chambers: 1. PGE2 - mucosal addition, 2. IL-1 $\beta-$ serosal addition, 3. IL-1 $\beta-$ mucosal addition. The concentration of PGE 2 and IL-1 $\beta$ in the chamber was $200 \mathrm{ng} / \mathrm{ml}$. The incubation time was 30 minutes.

II. According to the second approach, rats were anesthetized intraperitoneally with Zoletil 100 (Virbac, France, $100 \mathrm{mg} / \mathrm{kg}$ of the body weight). An incision was made along the midline of the abdomen from the processus xiphoideus of the sternum in the distal direction. Two ligatures isolated the colon loop between the cecum and the anus, thus limiting the colon and rectum. Two tubes were inserted at the beginning and at the end of the loop, and the system was filled hermetically with the test solution. A total of 8 male Wistar rats were randomly subdivided into two groups: an experimental and a control group. In the control group, the loop was filled with Krebs-Ringer's solution, while in the experimental group it was filled with PGE2 solution with $200 \mathrm{ng} /$ $\mathrm{ml}$ luminal. After $30 \mathrm{~min}$, the rats were decapitated, the large intestine was divided into segments as described above and continued to be incubated with PGE2 that was added to the mucosa side in Ussing chambers. The concentration of PGE2 in the chamber was $200 \mathrm{ng} / \mathrm{ml}$. Thus, the second methodological approach ensured a prolonged action of PGE2-initially in vivo, close to physiological conditions and then ex vivo. We suppose that the addition of PGE2 to the mucosa side and its prolonged action in vivo + ex vivo partially compensated the effect of the rapid enzymatic degradation of PGE2 by tissue cells.

\section{Electrophysiological parameters of the large intestinal wall}

The short circuit current (Isc) and transepithelial electrical resistance (TER) of the large intestine wall were studied according to a previously described protocol (Markov et al., 2016). Briefly, segments of the large in- 
testine were mounted in Ussing chambers filled with Krebs-Ringer solution at $37{ }^{\circ} \mathrm{C}$, which was maintained throughout the experiment, and permanently oxygenated with a mixture of $95 \%$ oxygen and $5 \%$ carbon dioxide. The Krebs-Ringer solution was composed as follows (mM): $\mathrm{NaCl}$ (119), $\mathrm{KCl}$ (5), $\mathrm{MgCl}_{2} \cdot 6 \mathrm{H}_{2} \mathrm{O}$ (1.2), $\mathrm{NaHCO}_{3}(25), \mathrm{NaH}_{2} \mathrm{PO}_{4} \cdot \mathrm{H}_{2} \mathrm{O}(0.4), \mathrm{Na}_{2} \mathrm{HPO}_{4} \cdot 7 \mathrm{H}_{2} \mathrm{O}$ (1.6), $\mathrm{CaCl}_{2}$ (1.2), and $\mathrm{D}$-glucose (10). The short circuit current was recorded when the voltage was $0 \mathrm{mV}$. To evaluate TER, we recorded voltage fluctuations when the current was $10 \mu \mathrm{A}$, and calculated it using Ohm's law:

$$
\mathrm{R}=\mathrm{U} / \mathrm{I}(\mathrm{Ohm})
$$

The size of the examined tissue was calculated by using the diameter of the slotted opening between the two chamber halves $(4 \mathrm{~mm})$, and was equal to $0.13 \mathrm{~cm}^{2}$. With regard to the size of the examined tissue, we adjusted the obtained transepithelial voltage values for $1 \mathrm{~cm}^{2}$ of tissue $\left(\mathrm{Ohm} \cdot \mathrm{cm}^{2}\right)$.

\section{Assessment of the paracellular permeability of the intestinal wall}

To study the paracellular permeability of the intestine in the Ussing chamber, we added sodium fluorescein to the mucosal bathing solution at a final concentration of $100 \mu \mathrm{M}$. This concentration was determined from earlier published reports (Zakelj et al., 2004; Molenda et al., 2014). Thirty minutes after the experiment started, the serosal bathing solution was removed to analyze the concentration of the diffused sodium fluorescein. To assess the optical density of this solution, we used a Cary Eclipse Fluorescence Spectrophotometer (Agilent, USA). The excitation and emission wavelengths were 460 and $515 \mathrm{~nm}$, respectively. The permeability coefficient $\left(\mathrm{P}_{\mathrm{app}}, \mathrm{cm} / \mathrm{s}\right)$ was calculated using the following equitation: $\mathrm{P}_{\text {app }}=(\mathrm{dQ} / \mathrm{dt}) /\left(\mathrm{A} \cdot \mathrm{C}_{0}\right)$, with:

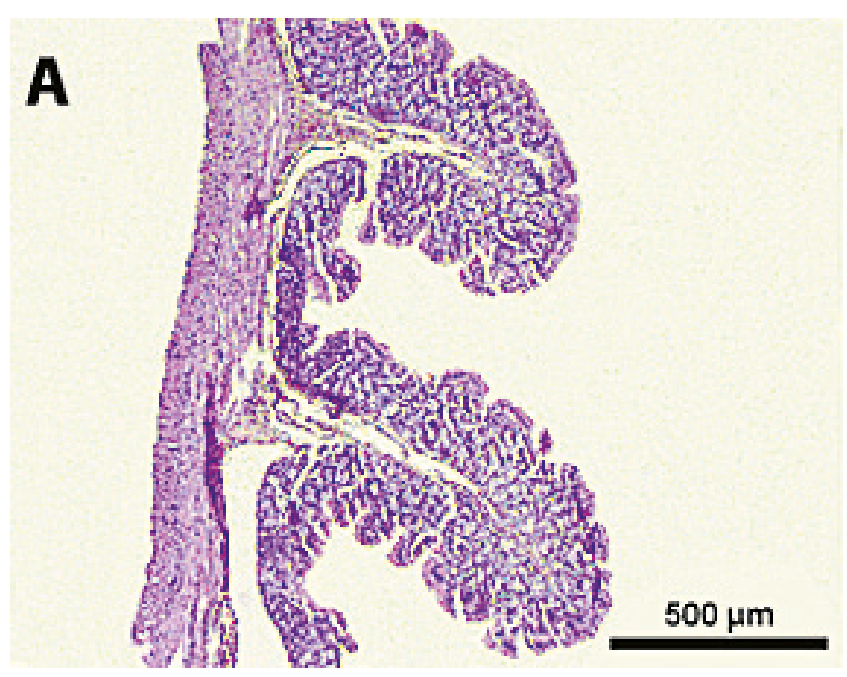

$\mathrm{dQ} / \mathrm{dt}$ as the concentration of fluorescein sodium in the serosal bathing solution $(\mathrm{mol} / \mathrm{s}), \mathrm{A}$ as the size of the examined tissue $\left(\mathrm{cm}^{2}\right)$, and $\mathrm{C}_{0}$ as the concentration of fluorescein sodium in the mucosal bathing solution.

\section{Optical microscopy and morphological analysis of the intestinal tissue samples}

In the ascending colon, the folds are arranged at angles to each other, forming a herringbone structure, whereas in the distal part of the descending colon the folds are absent (Fig. 1).

Optical microscopy was employed to analyze the ratio of proximal and distal colonic mucosal surface areas. The surface area of the mucosa of the proximal colon was measured by analyzing the surface area of the folds. The preparations were subjected to standard histological processing. Briefly, the tissue samples were fixed in $10 \%$ neutral buffered formalin and histologically processed for embedding in paraffin to prepare $\sim 5 \mu \mathrm{m}$-thick tissue sections, which were examined by H\&E staining and under a Leica DM IL LED Fluor Inverted Fluorescent Microscope.

The height of the folds was measured on the cross sections of the intestinal wall (Fig. 1, A). The length of the folds was measured through the circular excisions of the central part of the microphotos of the native samples with a radius of $2 \mathrm{~mm}$ according to the radius of the Ussing chamber aperture (Fig. 2). The lines marking the configuration of the folds were drawn by hand in Adobe Illustrator CC 23.0 (USA). Then, in the ImageJ editor (National Institutes of Health, USA), the lengths of the folds were measured. Using the measurements of the length and height of the folds, we calculated the surface area. The ratio of the surface area of the mucosa of the proximal part of the colon to the surface area of its distal part was taken as a factor for the correction of the

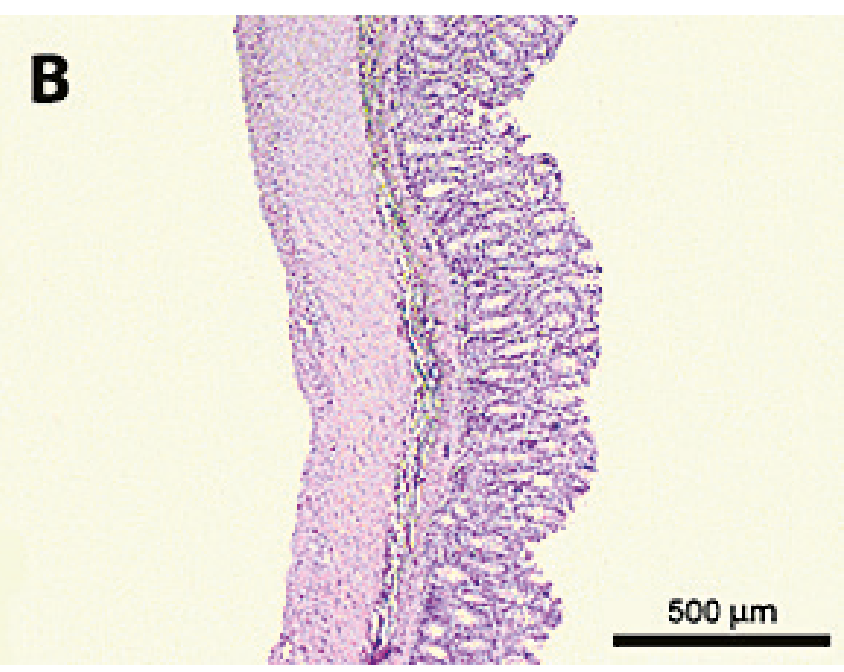

Fig. 1. Microphotographs of cross-sections of the intestinal wall in its proximal (A) and distal (B) parts (H\&E staining, scale bar $500 \mu \mathrm{m})$. 


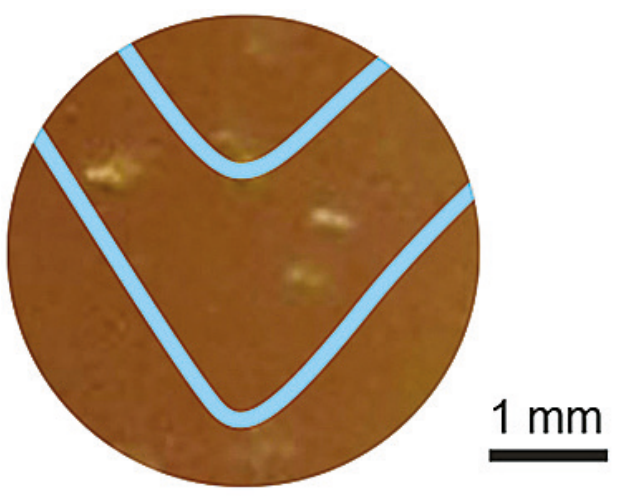

Fig. 2. Circular excision from the central part of the photo of the native sample $\left(S=0.13 \mathrm{~cm}^{2}\right)$ with lines along the contour of the folds.

values of short circuit current, transepithelial resistance and paracellular permeability for fluorescein sodium for the segments of the proximal part of the colon.

\section{Statistical analysis}

The data were analyzed using one-way ANOVA (Fig. 3) and non-parametric criterion Mann-Whitney U-test (Fig. 4, 5). The results of the analysis are presented as mean \pm standard error $(\mathrm{M} \pm \mathrm{SE})$. Statistically reliable differences were reported with a probability value of $95 \%(\mathrm{P}<0.05)$. Designations used hereinafter are as follows: $\mathrm{N}$ is the number of rats and $\mathrm{n}$ is the number of the colon segments.

\section{Results}

\section{Morphological analysis}

The height of the folds (h) of the mucosa in the proximal colon was $730 \pm 47 \mu \mathrm{m}$, while the length of the folds (L) was $9 \pm 0.3 \mathrm{~mm}$. The area of the folds was calculated using the formula: $S=2 \cdot h \cdot L$. Accordingly, the area of the lateral surfaces of the folds was $2 \cdot 0.733 \cdot 9=13 \mathrm{~mm}^{2}$. Thus, the folds of the mucosa in the proximal part of the colon doubled its surface area, the total area of the mucosa was $26 \pm 2 \mathrm{~mm}^{2}$, and the correction factor was two.

\section{Electrophysiological parameters and the paracellular permeability in the segments of the large intestinal wall}

The TER of the segments of the proximal colon was $112 \pm 12$ for segment "a" and $120 \pm 12 \mathrm{Ohm} \cdot \mathrm{cm}^{2}$ for segment " $b$ ". The TER was consistent with the TER value for the rat colon obtained in our previous studies (Markov et al., 2010; Markov and Amasheh, 2011; Bekusova et al., 2018) and in the works of other authors (Gitter et al., 2000; Amasheh et al., 2009). In the first distal segment "c", following the proximal part, the TER significantly decreased by half and amounted to $56 \pm 6 \mathrm{Ohm} \cdot \mathrm{cm}^{2}$. The TER of all other distal segments was also significantly less than the TER of the proximal colon segments (Fig. $3 \mathrm{~A}, \mathrm{~N}=7, \mathrm{n}=56$ ).

The Isc values in the two segments of the proximal part of the colon were lower compared to the distal part and rectum. The highest Isc in comparison with all other segments was determined for segment "f" (28.5 \pm $\left.7.5 \mu \mathrm{A} / \mathrm{cm}^{2}\right)$. The Isc of this segment was significantly different from all segments, except for the next segment "g" $\left(19.8 \pm 4 \mu \mathrm{A} / \mathrm{cm}^{2}\right)$ (Fig. $3 \mathrm{~B}, \mathrm{~N}=7, \mathrm{n}=56$ ).

The paracellular permeability of the proximal segments was lower than in the distal segments and rectum. Permeability of the first proximal segment "a" was $0.8 \pm$ $0.1 \cdot 10^{-4} \mathrm{~cm} / \mathrm{s}$ and significantly differed from the permeability of the three distal segments - "d", "f", "g" (5.9 \pm $0.810^{-4}, 5.4 \pm 0.810^{-4}, 5.7 \pm 1.1 \cdot 10^{-4} \mathrm{~cm} / \mathrm{s}$, respectively) and rectum. The permeability of the second proximal segment "b" was $0.96 \pm 0.3 \cdot 10^{-4} \mathrm{~cm} / \mathrm{s}$ and significantly differed from the permeability of the two distal segments ("d ", "g") and rectum (Fig. $3 \mathrm{C}, \mathrm{N}=5, \mathrm{n}=35$ ).

The reported data indicated significant reciprocal changes between TER and Isc for two proximal ("a" and "b") and two distal ("f" and "g") segments. The paracellular permeability for these segments was also different. Therefore, we pooled the data of both proximal segments to the proximal part and the data of two distal segments ("f" and "g") to the distal part; further we compared the parts between each other and used them as a control in studies ex vivo.

\section{Electrophysiological parameters and paracellular permeability for sodium fluorescein after incubation with PGE2 and IL-1beta in the proximal and distal parts of the colon}

Incubation of the intestinal segments in the Ussing chamber (ex vivo) is a widely established approach to studying the barrier properties of the epithelium (Clarke, 2009; He et al, 2013; Thomson et al., 2019).

In controls, the TER values of the proximal and distal parts of the colon remained stable during the whole timespan of the experiment (30 min), with $114 \pm$ $9 \mathrm{Ohm} \cdot \mathrm{cm}^{2}$ and $54 \pm 4 \mathrm{Ohm} \cdot \mathrm{cm}^{2}$, respectively $(\mathrm{p}<$ $0.0001, \mathrm{~N}=7, \mathrm{n}_{\text {prox }}=12, \mathrm{n}_{\text {dist }}=13$ ).

Isc in the proximal part was $6 \pm 1 \mu \mathrm{A} / \mathrm{cm}^{2}$, and in the distal part it was $24 \pm 4 \mu \mathrm{A} / \mathrm{cm}^{2}(\mathrm{p}<0.0001, \mathrm{~N}=7$, $\left.\mathrm{n}_{\text {prox }}=14, \mathrm{n}_{\text {dist }}=11\right)$. Paracellular permeability for sodium fluorescein was $0.9 \pm 0.2 \cdot 10^{-4}$ and $5 \pm 0.6 \cdot 10^{-4} \mathrm{~cm} / \mathrm{s}$, respectively $\left(\mathrm{p}<0.0001, \mathrm{~N}=7, \mathrm{n}_{\text {prox }}=9, \mathrm{n}_{\text {dist }}=10\right)$.

Administration of PGE2 $(200 \mathrm{ng} / \mathrm{ml}$ application to the mucosal side) ex vivo did not significantly affect TER and Isc both in the proximal and distal parts (Fig. 4 A, B). PGE2 treatment increased the TER in the proximal colon from $114 \pm 9$ to $158 \pm 22 \mathrm{Ohm} \cdot \mathrm{cm}^{2}$, but did not achieve a statistically significant difference 

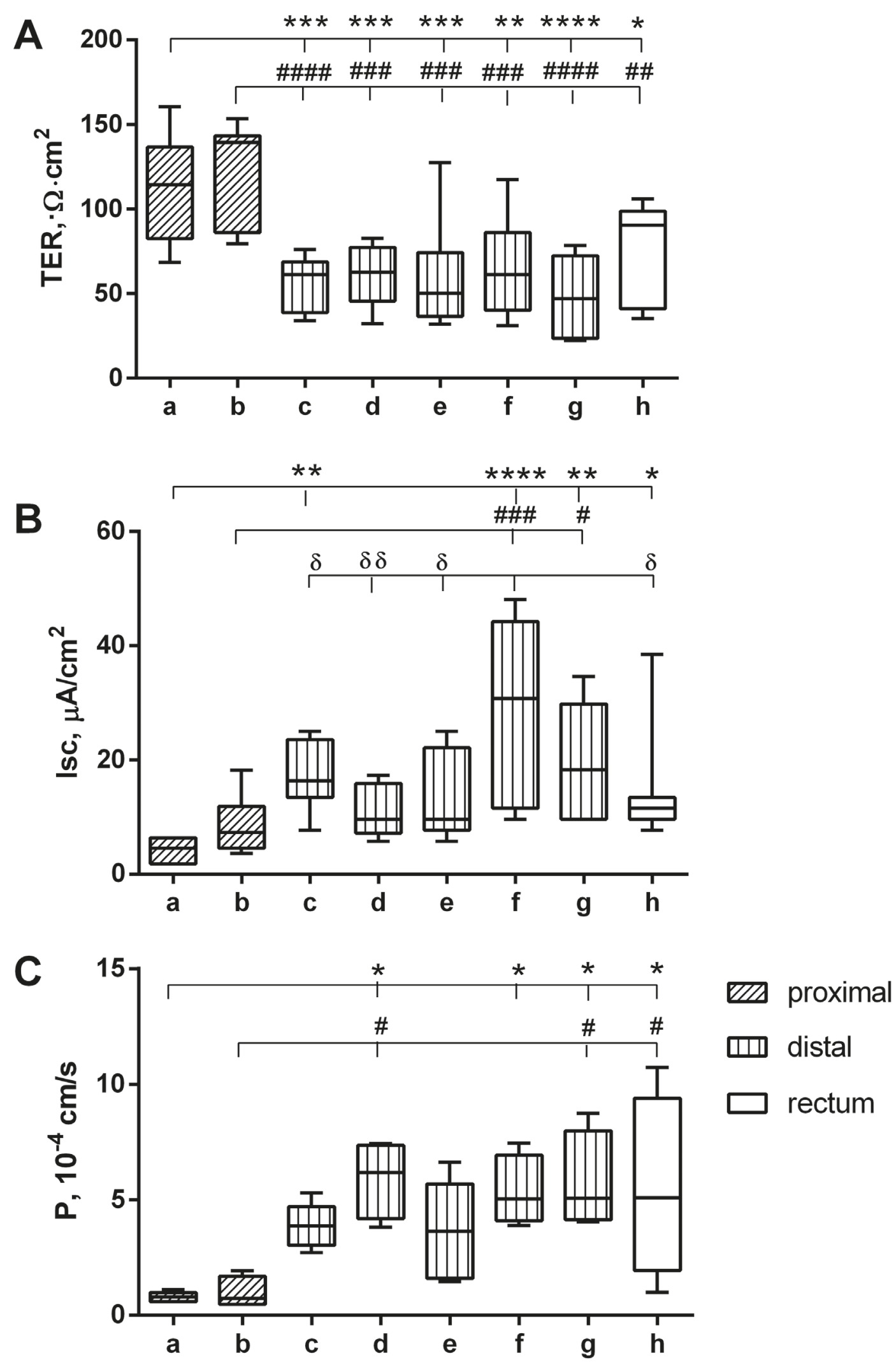

Fig. 3. A. Transepithelial resistance (TER), B. short circuit current (ISC), C. paracellular permeability for sodium fluorescein $(P)$ of the proximal segments "a" and "b" compared to the distal segments and rectum: "a" — * $p<0.05$,

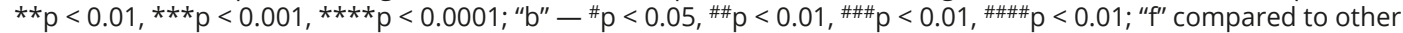
distal segments and rectum $-\delta p<0.05, \delta \delta p<0.01$, one-way ANOVA. 


\section{PGE2 ex vivo}
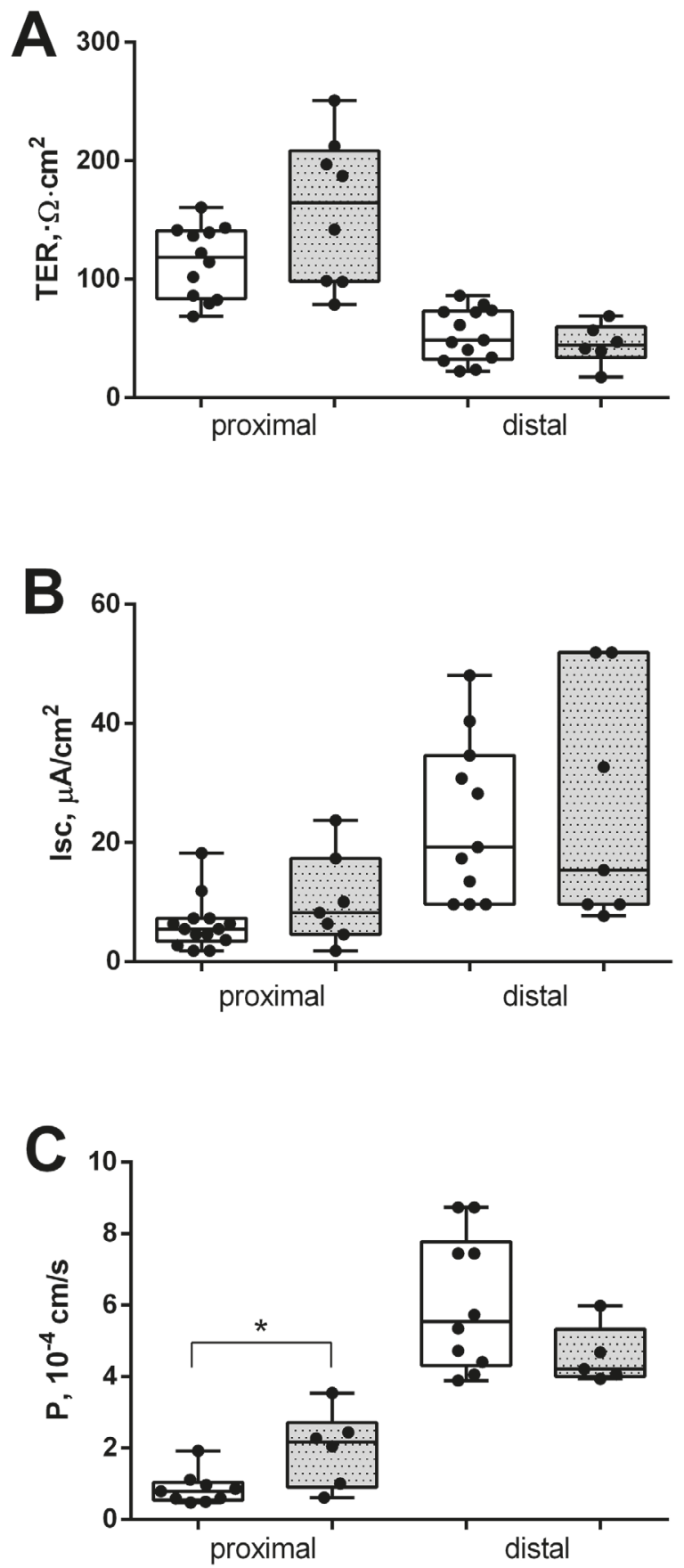

control

\section{PGE2 in vivo+ex vivo}
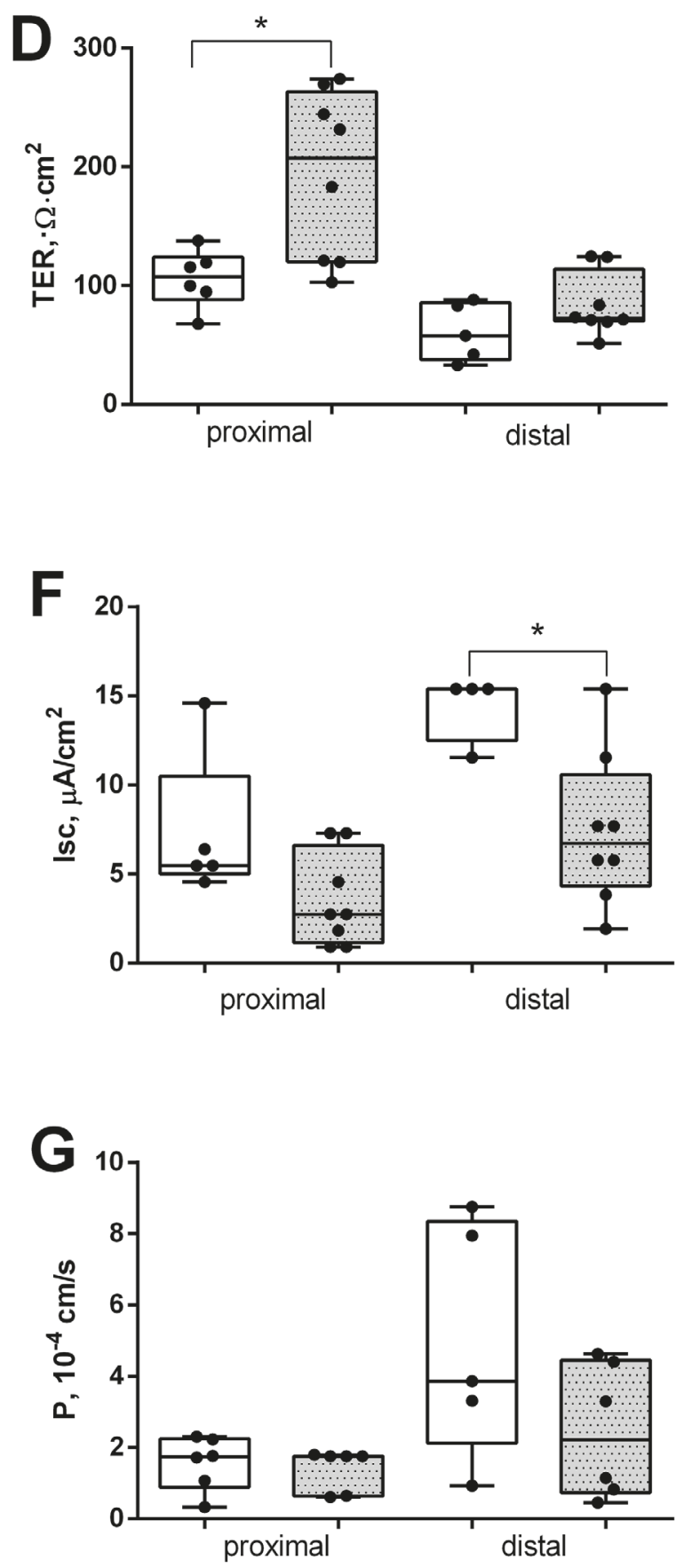

$\square$ PGE2

Fig. 4. Electrophysiological parameters and paracellular permeability for fluorescein sodium in the proximal and distal parts of the colon under action of PGE2: A, B, C - ex vivo, D, F, G - in vivo + ex vivo compared to the corresponding control groups, ${ }^{*} p<0.05$, Mann-Whitney U-test. 


\section{IL-1 $\beta$ to serosa}
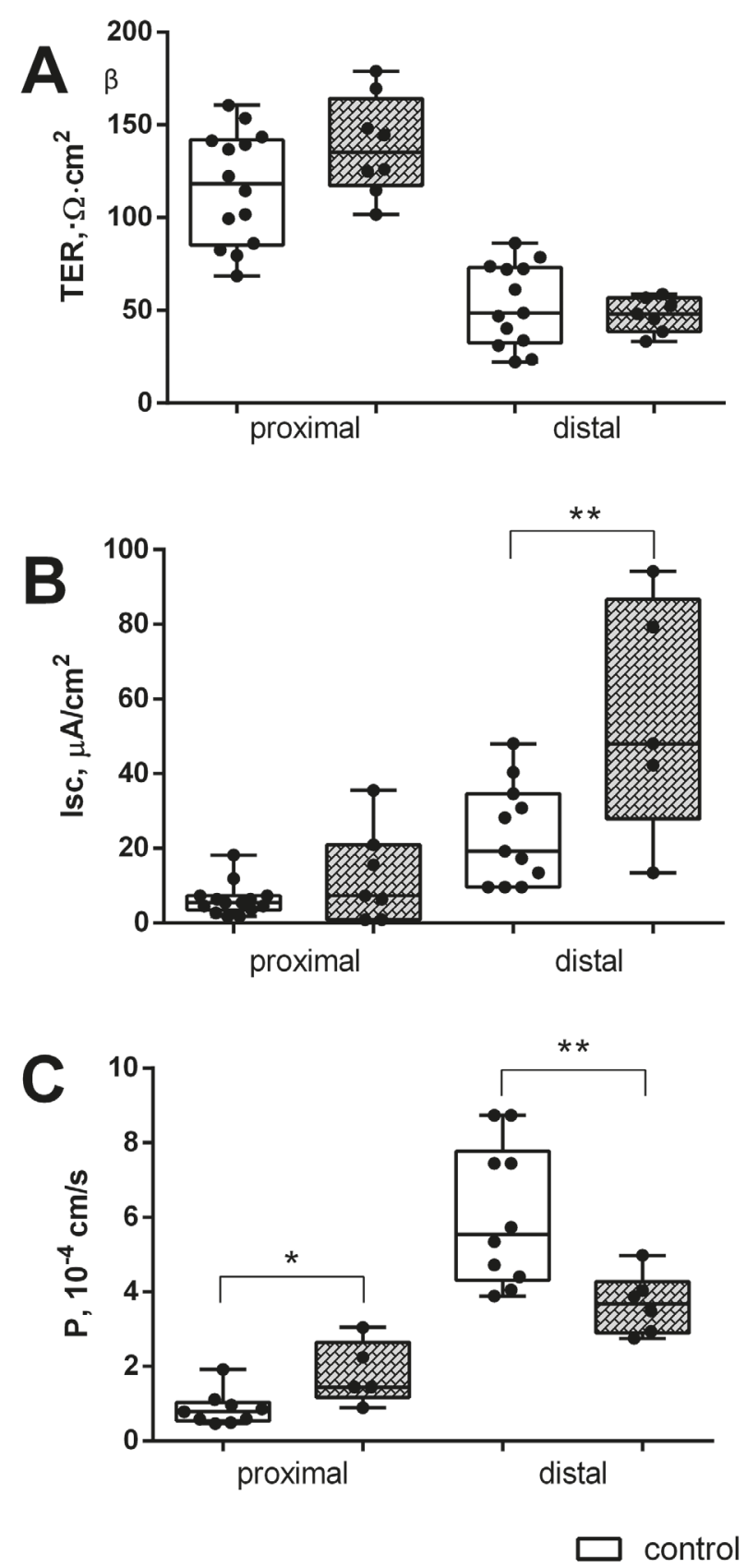

\section{IL-1 $\beta$ to mucosa}
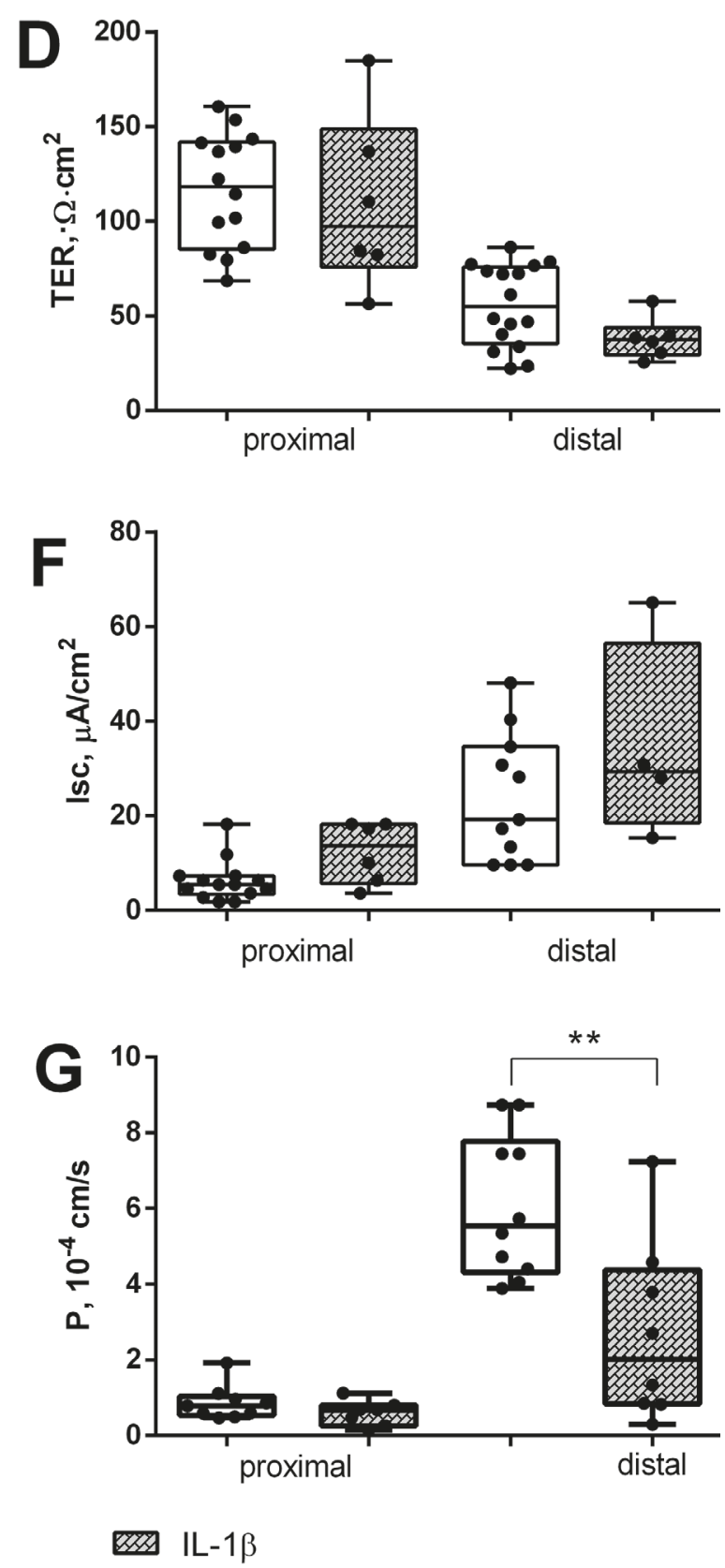

Fig. 5. Electrophysiological parameters and paracellular permeability for sodium fluorescein in the proximal and distal parts of the colon under action of IL-1B: A, B, C - from the serosa side D, F, G - from the mucosa side compared to the control group, ${ }^{*} \mathrm{p}<0.05,{ }^{* *} \mathrm{p}<0.01$, Mann-Whitney U-test.

(Fig. $4 \mathrm{~A}, \mathrm{p}=0.15, \mathrm{~N}=4, \mathrm{n}=8$ ). The paracellular flux of fluorescein sodium reflecting the restriction of diffusion of organic molecules along the paracellular pathway increased in the proximal part from $0.9 \pm 0.2$ to $2 \pm$ $0.410^{-4} \mathrm{~cm} / \mathrm{s}$ (Fig. $4 \mathrm{C}, \mathrm{p}<0.05, \mathrm{~N}=4, \mathrm{n}=6$ ). In contrast, the distal part was resistant against PGE2.

In the study in vivo + ex vivo, TER of the proximal and distal parts in the control was $106 \pm 10$ and $61 \pm$ $11 \mathrm{Ohm} \cdot \mathrm{cm}^{2}$, respectively, and significantly differed be- tween each other (Fig. $4 \mathrm{D}, \mathrm{p}<0.05, \mathrm{~N}=4, \mathrm{n}_{\text {prox }}=6$, $\mathrm{n}_{\text {dist }}=5$ ). Under incubation with PGE2, TER of the proximal part significantly increased to $193 \pm 25 \mathrm{Ohm} \cdot \mathrm{cm}^{2}$ (Fig. $4 \mathrm{D}, \mathrm{p}<0.05, \mathrm{~N}=4, \mathrm{n}=8$ ), while in the distal region it did not change. Thus, with the prolonged in vivo + ex vivo action, PGE2 had a more pronounced TER-increasing effect on the proximal part of the colon. In the control group, Isc was significantly different depending on the parts. In the proximal part, it was $7 \pm 2 \mu \mathrm{A} /$ 
$\mathrm{cm}^{2}$, while in the distal part it was $14 \pm 1 \mu \mathrm{A} / \mathrm{cm}^{2}$ (Fig. $4 \mathrm{~F}$, $\left.\mathrm{p}<0.05, \mathrm{~N}=4, \mathrm{n}_{\text {prox }}=5, \mathrm{n}_{\text {dist }}=8\right)$. Under incubation with PGE2, the Isc in the distal region significantly decreased to $7 \pm 1 \mu \mathrm{A} / \mathrm{cm}^{2}$ and did not change in the proximal region (Fig. 4 F, p $<0.05, \mathrm{~N}=4, \mathrm{n}_{\text {prox }}=4$, $\mathrm{n}_{\text {dist }}=8$ ).

Paracellular permeability was not significantly changed by PGE2 (Fig. 4 G).

Thus, the prolonged in vivo + ex vivo action of PGE2 led to a change in both electrophysiological parameters, with TER increasing only in the proximal part and Isc decreasing only in the distal part of the colon.

IL-1 $\beta(200 \mathrm{ng} / \mathrm{ml})$ did not affect the electrophysiological parameters of the proximal colon regardless of the side of stimulation (Fig. 5 A, B, D, F).

In the distal part of the colon, TER did not change after incubation with IL- $1 \beta$, and the Isc significantly increased from $24 \pm 4$ to $55 \pm 14 \mu \mathrm{A} / \mathrm{cm}^{2}$, only when applied to the serosal side (Fig. $5 \mathrm{~B}, \mathrm{p}<0.05, \mathrm{~N}=4, \mathrm{n}=5$ ).

The paracellular permeability for sodium fluorescein was changed by IL- $1 \beta$ and depended on the part of the colon. In the proximal colon, the permeability significantly increased from $0.9 \pm 0.2 \cdot 10^{-4}$ to $1.8 \pm 0.4 \cdot 10^{-4} \mathrm{~cm} / \mathrm{s}$, if applied from the serosa side (Fig. $5 \mathrm{C}, \mathrm{p}<0.05, \mathrm{~N}=4, \mathrm{n}=5$ ). While in the distal colon, the permeability significantly decreased. If IL- $1 \beta$ was applied to the serosa side, it decreased from $5 \pm 0.6 \cdot 10^{-4}$ to $3.7 \pm 0.3 \cdot 10^{-4} \mathrm{~cm} / \mathrm{s}$ (Fig. $5 \mathrm{C}$, $\mathrm{p}<0.01, \mathrm{~N}=4, \mathrm{n}=8$ ), and if it was applied to the mucosa side, it decreased from $5 \pm 0.6 \cdot 10^{-4}$ to $2.7 \pm 0.84 \cdot 10^{-4} \mathrm{~cm} / \mathrm{s}$ (Fig. $5 \mathrm{G}, \mathrm{p}<0.01, \mathrm{~N}=3, \mathrm{n}=8$ ).

\section{Discussion}

Our previous research findings showed that the comparative study of different parts of the colon requires precise measurement of the surface area of the tissue samples and the use of a calculated correction factor (Bekusova et al., 2018). Morphometric analysis showed that, due to the folds, the surface area of the samples of the proximal part of the rat colon was twice that of the distal one. The parameters of the intestinal permeability studied in the Ussing chamber directly depended on the number of ion channels and intercellular contacts which were located in the aperture of the Ussing chamber during the study; therefore, the comparative analysis of the permeability parameters required their correction for the proximal colon. The use of the correction factor made it possible to carry out a correct comparative analysis of the permeability parameters of the colon and to reveal significant differences between its segments.

The present study shows that in Wistar rats aged 1.5 months, the proximal part of the colon, unlike its distal part, shows a significantly higher transepithelial resistance, lower short-circuit current, and reduced paracellular permeability. These data indicate more pronounced barrier properties of the proximal part of the colon in comparison with the distal one and the heterogeneity of the barrier properties of different parts of the colon. This heterogeneity can be explained both by how electrolytes are transported and how the ionic transport is regulated. For example, in the proximal colon, $\mathrm{Na}^{+}$ movement occurs via electroneutral $\mathrm{Na}^{+}$absorption, while in the distal part it is mostly associated with the amiloride-sensitive and aldosterone-regulated sodium transport (Sandle et al., 1986; Parkin et al., 2005). Considering the key role of the microbiota in the colon, it is possible that the more pronounced barrier properties of the proximal colon are due to the increased production of microflora - butyrate and other short-chain fatty acids, which enhance the barrier properties of the colon (Canani et al., 2011).

We assume that the heterogeneity of the barrier properties of the colon is one of the factors that determine how pathological processes will develop, while one of the aspects of this heterogeneity may be different effects produced by the regulatory chemical agents which may be elevated in bowel diseases.

Previously, the effect of PGE2 on barrier properties was investigated in Caco-2 (Tanaka et al., 2008; Lejeune et al., 2010; Rodriguez-Lagunas et al., 2010) and T84 (Lejeune et al., 2010) epithelial cells. PGE2 has been shown to impair the barrier function in Caco2 cell monolayers, resulting in a decrease of TER and an increase of permeability to D-mannitol (Lejeune et al., 2010) or ruthenium red (Tanaka et al., 2008). In our work, we investigated, for the first time, the effects of PGE2 on the barrier properties of different parts of the colon in the Ussing chamber.

The employed concentration of PGE2 (200 nM) was higher compared to the physiological concentration of PGE2, which was around $10 \mathrm{nM}$ (Flores-Benitez et al., 2009), but it was below the average value in the range of increased concentrations. It was shown that in inflamed intestinal mucosa, PGE2 increased 10- to 100fold (Stenson et al, 2001). Most authors used an even higher $-1 \mu \mathrm{M}-$ concentration of PGE2 in the studies, presuming that the high concentration of PGE2 had biological relevance (Tanaka et al., 2008; Lejeune et al., 2010; Digiacomo et al., 2015).

Electrophysiological study of the rat colon under the action of PGE2 showed an increase in transepithelial resistance in the ascending part and a decrease in short-circuit current in the segments of the descending part, which indicated a decrease of absorption in the proximal part and a decrease of active transport in the distal part of the colon. The paracellular permeability of the proximal region increased under the action of PGE2, which might indicate its effect on the structure of tight junctions; however, this result was obtained only in ex vivo study and was not confirmed by its prolonged in vivo + ex vivo action. 
Based on the literature, PGE2 promotes the reversal of the direction of ion transport of $\mathrm{Na}^{+}$and $\mathrm{Cl}^{-}$ from absorption to secretion. The mechanism may be based on an activation of CFTR chloride channels and an increase in cAMP, leading to inhibition of absorption (Kunzelmann and Mall, 2002). The effects of PGE2 were manifested in enhancing the barrier properties of the colon. However, different parameters of the permeability changed in different parts of the colon. The effect of PGE2 on the electrophysiological properties was revealed only with its prolonged in vivo + ex vivo action, which indicated a greater adequacy of this model in our study.

Taking into consideration the possible concentration and time effects of PGE2, we suppose that the results of our study are largely due to the properties of the object that we study. The data contradicting the results obtained by researchers when studying the effect of PGE2 on the barrier properties of cell cultures can be explained by a significant decrease in the localization of EP4 in some cultures of intestinal epithelium cells, in particular, in Caco-2 (Shoji et al., 2004). All types of PGE2 receptors are localized in the colon wall; however, the barrier function in healthy colonic mucosa predominantly is determined by EP4 receptors localized on the apical plasma membrane of epithelial cells at the tip of the mucosal folds (Lejeune et al., 2010). Interestingly, in colorectal cancer the number of these receptors remains unchanged, while the number of the other types of PGE2 receptors is subject to change (Shoji et al., 2004). EP4 is not limited to regulation of the barrier function. It has been shown that this receptor type stimulates the growth of cell colonies in the human colon adenocarcinoma HCA-7 cell line. Furthermore, in EP4 KO mice that were treated by azoxymethane, there was a twofold decrease in the number of aberrant crypts as compared to wild-type mice (Mutoh et al., 2002). The relationship between the impairment of the barrier function under the influence of PGE2 and the development of pathologies has not yet been revealed. It is obvious that PGE2 has an effect on the barrier function of the colon and, as the results of our study have shown, does not equally affect the parameters of the barrier properties of its different departments.

IL- $1 \beta$ is one of the main pro-inflammatory protumor cytokines, which increases during carcinogenesis of various organs, including colorectal cancer (Zielinska et al., 2018). The authors testify to the disruption of barrier properties of various tissues under the influence of IL-1 $\beta$, which has a direct effect on the expression of tight junction proteins, resulting in an increase in $\mathrm{TJ}$ permeability (Duffy et al., 2000; Coyne et al., 2002; Yamagata et al., 2004; Al-Sadi, Boivin and Ma, 2009). Although the effects of IL- $1 \beta$ have been studied in many organs, including the small intestine, and in the culture of Caco-2 cells (Al-Sadi et al., 2013), we have not found any published data on its effect on the barrier properties of the colon, with the exception of its influence on shortcircuit current in the study by Bode et al. (1998).

In our study, IL-1 $\beta$ had no effect on the electrophysiological properties of the proximal part of the colon, while in the distal part it significantly increased the short-circuit current when applied to the basolateral side of epithelial cells, which was consistent with the data of Bode et al. (1998). Increased paracellular permeability was observed only in the proximal part of the colon and only when IL- $1 \beta$ was applied to the basolateral side. In the distal part, IL- $1 \beta$ reduced the paracellular permeability to fluorescein sodium both from the basolateral and apical side of the epithelium.

An increase in the short-circuit current by IL- $1 \beta$ indicated its stimulating effect on the active absorption of sodium through the basolateral membrane in the distal colon. At the same time, the TER did not change, while the paracellular permeability decreased. It is possible that the permeability for uncharged macromolecules of sodium fluorescein was shunted by an increased current of ions which was caused by electrogenic $\mathrm{Na}^{+}$channels localized only in the distal part of the colon. The assumed increase in sodium absorption through these channels could lead to an increase of the negative charge of the outer side of the apical membrane, which should have facilitated the absorption of $\mathrm{Cl}^{-}$transported in the distal colon both trans- and paracellularly (Kunzelmann and Mall, 2002). Although these hypotheses are not proved on the basis of our data, it is strongly supported by the general understanding of the mechanisms of electrolyte transport, based on the results of studies (Kunzelmann and Mall, 2002). The effect of IL- $1 \beta$ on the paracellular permeability of the distal colon was similar to the basolateral and apical sides, indirectly indicating its impact on the structure of tight junctions. The opposite effect on the paracellular permeability of the proximal colon indicates a different effect of IL- $1 \beta$ on the permeability of the proximal and distal parts of the colon.

Thus, the proximal part of the rat colon was characterized by more pronounced barrier properties in comparison with the distal one. PGE2 enhanced the barrier properties of the colon, affecting various permeability parameters in its different parts. IL- $1 \beta$ stimulated active transport in the distal colon, yet it decreased its paracellular permeability and regulated paracellular permeability of the proximal colon in the opposite way.

The results of our study indicate that both PGE2 and IL- $1 \beta$ have different effects on the barrier properties of the proximal and distal parts of the large intestine in healthy rats, which reveals the heterogeneity of the properties of the colon. Different, sometimes opposite, effects of the regulation of the colonic epithelial properties by local molecular agents can indicate different 
mechanisms of development of pathological processes in different parts of this organ. The study of the heterogeneity of the properties and effects of the regulation of colonic functions will contribute to the prevention, diagnosis and treatment of pathology.

\section{Acknowledgments}

Scientific research was performed at the Research Park of St. Petersburg State University Center for Molecular and Cell Technologies. We are grateful to Associate Professor Irina A. Lekomtseva, Department of English Philology and Translation, St Petersburg University, for help during translation of this article.

\section{References}

Abe, T., Sugano, E., Saigo, Y., and Tamai, M. 2003. Interleukin-1 beta and barrier function of retinal pigment epithelial cells (ARPE-19): Aberrant expression of junctional complex molecules. Investigative Ophthalmology \& Visual Science 44(9):4097-4104. https://doi.org/10.1167/iovs.02-0867

Al-Sadi, R., Boivin, M., and Ma, T. 2009. Mechanism of cytokine modulation of epithelial tight junction barrier. Frontiers in Bioscience 14(1):2765-2778. https://doi. org/10.2741/4013

Al-Sadi, R., Guo S., Dokladny, K., Smith, M., Ye, D., Kaza, A., Watterson, D., and Ma, T. 2012. Mechanism of interleukin-1 beta induced-increase in mouse intestinal permeability in vivo. Journal of Interferon and Cytokine Research 32(10):474-484. https://doi.org/10.1089/jir.2012.0031

Al-Sadi, R., Guo, S., Ye, D., Dokladny, K., Alhmoud, T., Ereifej, L., Said, H., and Ma, T. 2013. Mechanism of IL-1b modulation of intestinal epithelial barrier involves P38 kinase and activating transcription factor-2 activation. Journal of Immunology 190(12):6596-6606. https:// doi.org/10.4049/jimmunol.1201876

Amasheh, M., Grotjohann, I., Amasheh, S., Fromm, A., Soderholm, J., Zeitz, M., Fromm, M., and Schulzke, J. 2009. Regulation of mucosal structure and barrier function in rat colon exposed to tumor necrosis factor alpha and interferon gamma in vitro: a novel model for studying the pathomechanisms of inflammatory bowel disease cytokines. Scandinavian Journal of Gastroenterology 44(10):1226-1235. https://doi. org/10.1080/00365520903131973

Bekusova, V., Falchuk, E., Okorokova, L., Kruglova, N., Nozdrachev, A., and Markov, A. 2018. Increased paracellular permeability of tumor-adjacent areas in 1,2-dimethylhydrazine-induced colon carcinogenesis in rats. Cancer Biology and Medicine 15(3):251-259. https://doi. org/10.20892/j.issn.2095-3941.2018.0016

Bekusova, V., Patsanovskii, V., Nozdrachev, A., Trashkov, A., Artemenko, M., and Anisimov, V. 2017. Metformin prevents hormonal and metabolic disturbances and 1,2-dimethylhydrazine-induced colon carcinogenesis in nondiabetic rats. Cancer Biology and Medicine 14(1):100-107. https://doi.org/10.20892/j.issn.2095-3941.2016.0088

Bode, H., Schmitz, H., Fromm, M., Scholz, P., Riecken, E., and Schulzke, J. 1998. IL-1 beta and TNF-alpha, but not IFNalpha, IFN-gamma, IL-6 or IL-8, are secretory mediators in human distal colon. Cytokine 10(6):457-465. https:// doi.org/10.1006/cyto.1997.0307

Brosnahan, A. and Brown, D. 2012. Porcine IPEC-J2 intestinal epithelial cells in microbiological investigations. Veterinary Microbiology 156(3-4):229-237. https://doi. org/10.1016/j.vetmic.2011.10.017
Canani, R., Costanzo, M., Leone, L., Pedata, M., Meli, R., and Calignano, A. 2011. Potential beneficial effects of butyrate in intestinal and extrainitestinal diseases. World Journal of Gastroenterology 17(12):1519-1528. https://doi. org/10.3748/wjg.v17.i12.1519

Capone, F., Guerriero, E., Sorice, A., Colonna, G., Ciliberto, G., and Costantini, S. 2016. Serum cytokinome profile evaluation: a tool to define new diagnostic and prognostic markers of cancer using multiplexed bead-based immunoassays. Mediators of Inflammation 2016:3064643. https://doi.org/10.1155/2016/3064643

Carmi, Y., Dotan, S., Rider, P., Kaplanov, I., White, M., Baron, R., Abutbul, S., Huszar, M., Dinarello, C., Apte, N., and Voronov, E. 2013. The role of II-1 beta in the early tumor cell-induced angiogenic response. Journal of Immunology 190(7):3500-3509. https://doi.org/10.4049/jimmunol.1202769

Clarke, L. 2009. A guide to Ussing chamber studies of mouse intestine. American Journal of Physiology-Gastrointestinal and Liver Physiology 296(6):G1151-G1166. https://doi. org/10.1152/ajpgi.90649.2008

Clauss, W. and Hornicke, H. 1984. Segmental differences in K-transport across rabbit proximal and distal coIon in vivo and in vitro. Comparative Biochemistry and Physiology Part A: Physiology 79(2):267-269. https://doi. org/10.1016/0300-9629(84)90427-4

Coyne, C., Vanhook, M., Gambling, T., Carson, J., Boucher, R., and Johnson, L. 2002. Regulation of airway tight junctions by proinflammatory cytokines. Molecular Biology of the Cell 13(9):3218-3234. https://doi.org/10.1091/mbc. E02-03-0134

Digiacomo, G., Ziche, M., Dello Sbarba, P., Donnini, S., and Rovida, E. 2015. Prostaglandin E2 transactivates the colony-stimulating factor-1 receptor and synergizes with colony-stimulating factor-1 in the induction of macrophage migration via the mitogen-activated protein $\mathrm{ki}-$ nase ERK1/2. FASEB JOURNAL 29(6):2545-2554. https:// doi.org/10.1096/fj.14-258939

Duffy, H., John, G., Lee, S., Brosnan, C., and Spray, D. 2000. Reciprocal regulation of the junctional proteins claudin-1 and connexin43 by interleukin-1 beta in primary human fetal astrocytes. Journal of Neuroscience 20(23):RC114. https://doi.org/10.1523/JNEUROSCI. 20-23-j0004.2000

Edmonds, C. 1967. Gradient of electrical potential difference and of sodium and potassium of gut contents along caecum and colon of normal and sodium-depleted rats. The Journal of Physiology 193(3):571. https://doi.org/10.1113/ jphysiol.1967.sp008379

Flores-Benitez, D., Rincon-Heredia, R., Razgado, L., Larre, I., Cereijido, M., and Contreras R. 2009. Control of tight junctional sealing: roles of epidermal growth factor and prostaglandin E-2. American Journal of Physiology-Cell Physiology 297(3):C611-C620. https://doi.org/10.1152/ ajpcell.00622.2008

Fromm, M. and Hegel, U. 1978. Segmental heterogeneity of epithelial transport in rat large-intestine. Pflügers Archiv 378(1):71-83. https://doi.org/10.1007/bf00581960

Gitter, A., Bendfeldt, K., Schulzke, J., and Fromm, M. 2000. trans/paracellular, surface/crypt, and epithelial/subepithelial resistances of mammalian colonic epithelia. Pflügers Archiv 439(4):477-482. https://doi.org/10.1007/ s004240050966

He, L. Yin, Y., Li, T., Huang, R., Xie, M., Wu, Z., and Wu, G. 2013. Use of the Ussing chamber technique to study nutrient transport by epithelial tissues. Frontiers in Bioscience 18:1266-1275. https://doi.org/10.2741/4178

Kamiyama, M., Pozzi, A., Yang, L., DeBusk, L., Breyer, R., and Lin, P. 2006. EP2, a receptor for PGE(2), regulates tu- 
mor angiogenesis through direct effects on endothelial cell motility and survival. Oncogene 25(53):7019-7028. https://doi.org/10.1038/sj.onc.1209694

Kunzelmann, K. and Mall, M. 2002. Electrolyte transport in the mammalian colon: mechanisms and implications for disease. Physiological Reviews 82(1):245-289. https://doi. org/10.1152/physrev.00026.2001

Lejeune, M., Leung, P., Beck, P., and Chadee, K. 2010. Role of EP4 receptor and prostaglandin transporter in prostaglandin E-2-induced alteration in colonic epithelial barrier integrity. American Journal of Physiology-Gastrointestinal and Liver Physiology 299(5):G1097-G1105. https:// doi.org/10.1152/ajpgi.00280.2010

Mahler, M., Berard, M., Feinstein, R., Gallagher, A., IllgenWilcke, B., Pritchett-Corning, K., Raspa, M., and FELASA Working Group Revision. 2014. FELASA recommendations for the health monitoring of mouse, rat, hamster, guinea pig and rabbit colonies in breeding and experimental units. Laboratory Animals 48(3):178-192. https:// doi.org/10.1177/0023677213516312

Markov, A. and Amasheh, S. 2011. Barrier properties and tight junction protein expression along the longitudinal axis of rat intestine. Neuroscience and Behavioral Physiology - Sechenov Physiology Journal 97(10):1066-1083.

Markov, A., Falchuk, E., Kruglova, N., Radloff, J., and Amasheh, S. 2016. Claudin expression in follicle-associated epithelium of rat Peyer's patches defines a major restriction of the paracellular pathway. Acta Physiologica 216(1):112-119. https://doi.org/10.1111/apha.12559

Markov, A., Veshnyakova, A., Fromm, M., Amasheh, M., and Amasheh, S. 2010. Segmental expression of claudin proteins correlates with tight junction barrier properties in rat intestine. Journal of Comparative Physiology B-Biochemical Systemic and Environmental Physiology 180(4):591-598. https://doi.org/10.1007/s00360-009-0440-7

Molenda, N., Urbanova, K., Weiser, N., Kusche-Vihrog, K., Gunzel, D., and Schillers, H. 2014. Paracellular transport through healthy and cystic fibrosis bronchial epithelial cell lines - do we have a proper model? PLOS ONE 9(6). https://doi.org/10.1371/journal.pone.0100621

Mutoh, M., Watanabe, K., Kitamura, T., Shoji, Y., Takahashi, M., Kawamori, T., Tani, K., Kobayashi, M., Maruyama, T., Kobayashi, K., Ohuchida, S., Sugimoto, Y., Narumiya, S., Sugimura, T., and Wakabayashi, K. 2002. Involvement of prostaglandin E receptor subtype EP4 in colon carcinogenesis. Cancer Research 62(1):28-32.

Parkin, D., Bray, F., Ferlay, J., and Pisani, P. 2005. Global cancer statistics, 2002. CA: A Cancer Journal for Clinicians 55(2):74-108. https://doi.org/10.3322/canjclin.55.2.74

Perse, M. and Cerar, A. 2011. Morphological and molecular alterations in 1,2 dimethylhydrazine and azoxymethane induced colon carcinogenesis in rats. Journal of Biomedicine and Biotechnology 2011:473964. https://doi. org/10.1155/2011/473964

Rodriguez-Lagunas, M., Martin-Venegas, R., Moreno, J., and Ferrer, R. 2010. Pge(2) promotes $\mathrm{Ca}^{2+}$-mediated epithelial barrier disruption through EP1 and EP4 receptors in Caco-2 cell monolayers. American Journal of Physiology-Cell Physiology 299(2):C324-C334. https://doi. org/10.1152/ajpcell.00397.2009

Rubsamen, K., Hume, I., Foley, W., and Rubsamen, U. 1983. Regional differences in electrolyte, short-chain fatty-acid and water-absorption in the hindgut of 2 species of ar- boreal marsupials. Pflügers Archiv 399(1):68-73. https:// doi.org/10.1007/bf00652524

Safdari, B., Sia, T., Wattchow, D., and Smid, S. 2016. Effects of pro-inflammatory cytokines, lipopolysaccharide and COX-2 mediators on human colonic neuromuscular function and epithelial permeability. Cytokine 83:231238. https://doi.org/10.1016/j.cyto.2016.04.017

Sandle, G., Wills, N., Alles, W., and Binder, H. 1986. Electrophysiology of the human-colon - evidence of segmental heterogeneity. Gut 27(9):999-1005. https://doi. org/10.1136/gut.27.9.999

Sheng, G., Shao, J., Mifflin, R., Powell, D., and Sheng, H. 2006. Prostaglandin E2 stimulates intestinal epithelial proliferation and migration through activation of intestinal subepithelial myofibroblasts. Gastroenterology 130(4):A96A96.

Shoji, Y., Takahashi, M., Kitamura, T., Watanabe, K., Kawamori, T., Maruyama, T., Sugimoto, Y., Negishi, M., Narumiya, S., Sugimura, T., and Wakabayashi, K. 2004. Downregulation of prostaglandin E receptor subtype EP3 during colon cancer development. Gut 53(8):1151-1158. https://doi.org/10.1136/gut.2003.028787

Stenson, W., Zhang, Z., Riehl, T., and Stanley, S. 2001. Amebic infection in the human colon induces cyclooxygenase- 2 . Infection and Immunity 69(5):3382-3388. https://doi. org/10.1128/iai.69.5.3382-3388.2001

Tanaka, M., Diaz, B., de Souza, W., and Morgado-Diaz, J. 2008. Prostaglandin EP-EP1 and EP2 receptor signaling promotes apical junctional complex disassembly of Caco2 human colorectal cancer cells. BMC Cell Biology 9. https://doi.org/10.1186/1471-2121-9-63

Thomson, A., Smart, K., Somerville, M., Lauder, S., Appanna, G., Horwood, J., Raj, L., Srivastava, B., Durai, D., Scurr, M., Keita, A., Gallimore, A., and Godkin, A. 2019. The Ussing chamber system for measuring intestinal permeability in health and disease. BMC Gastroenterology 19. https://doi.org/10.1186/s12876-019-1002-4

Voronov, E., Dotan, S., Krelin, Y., Song, X., Elkabets, M., Carmi, Y., Rider, P., Cohen, I., Romzova, M., Kaplanov, I., and Apte, R. 2013. Unique versus redundant functional of IL-1 alpha and IL-1 beta in the tumor microenvironment. Frontiers in Immunology 4. https://doi.org/10.3389/fimmu.2013.00177

Yamagata, K., Tagami, M., Takenaga, F., Yamori, Y., and Itoh, S. 2004. Hypoxia-induced changes in tight junction permeability of brain capillary endothelial cells are associated with II-1 beta and nitric oxide. Neurobiology of Disease 17(3):491-499. https://doi.org/10.1016/j. nbd.2004.08.001

Yau, W. and Makhlouf, G. 1975. Comparison of transport mechanisms in isolated ascending and descending rat colon. American Journal of Physiology 228(1):191-195. https://doi.org/10.1152/ajplegacy.1975.228.1.191

Zakelj, S., Legen, I., Veber, M., and Kristl, A. 2004. The influence of buffer composition on tissue integrity during permeability experiments "in vitro". International Journal of Pharmaceutics 272(1-2):173-180. https://doi.org/10.1016/j. ijpharm.2003.12.014

Zielinska, K., Kwasniak, K., Tabarkiewicz, J., and KarczmarekBorowska, B. 2018. The role of pro-inflammatory cytokines in the pathogenesis and progression of neoplasms. Postepy Higieny I Medycyny Doswiadczalnej 72:896-905. https://doi.org/10.5604/01.3001.0012.6931 